\title{
Vivências e percepções dos estágios pedagógicos: estudo com alunos de licenciaturas em ensino
}

\author{
Susana Caires ${ }^{1}$ \\ Leandro S. Almeida ${ }^{2}$
}

\begin{abstract}
Resumo
Centrado na última etapa da formação inicial de professores - os estágios pedagógicos - o presente trabalho explora alguns dos aspectos mais significativos da estreia na profissão docente. Incidindo na perspectiva dos professoresestagiários, o repertório explorado abarca as principais vivências e percepções associadas ao "Tornar-se-professor", dando a conhecer alguns dos maiores ganhos e dificuldades inerentes a este processo. Tomando as respostas de 229 professores-estagiários da Universidade do Minho no Inventário de Vivências e Percepções de Estágio (Versão para as Licenciaturas em Ensino), aplicado no início e no final do estágio, detectaram-se oscilações positivas na forma como os professores-estagiários vivenciam esta etapa formativa. Entre as cinco dimensões do questionário ("Socialização Profissional e Institucional”, "Aspectos Sócio-Emocionais", "Aprendizagem e Desenvolvimento Profissional”, "Apoio/Recursos/Supervisão" e "Aspectos Vocacionais"), destaquem-se os maiores níveis de satisfação e ganho percebidos pelos sujeitos nas dimensões "Socialização Profissional e Institucional", "Aprendizagem e Desenvolvimento Profissional" e "Aspectos Vocacionais".

Palavras-Chave: Estágio; Desenvolvimento de jovens-adultos; Transição universidade-trabalho; Formação de professores.
\end{abstract}

\section{Experiences and perceptions during practicum: A study with preservice teachers}

\begin{abstract}
Focusing on the last stage of the Initial Teacher Education - the practicum experience/preservice program - this paper explores some of the most significant aspects of the initial teaching experience. Concentrating on preservice teacher's perspectives, the paper encloses the main experiences and perceptions related to "becoming a teacher", presenting some of the major gains and difficulties inherent to this process. The answers of a group of 229 student teachers from Minho University to the "Inventory of Experiences and Perceptions at Practicum" (Version for Teacher Education Students), applied at the beginning and at the end of the practicum, showed positive oscillations in the way student teachers live this stage of their professional development. Among the five dimensions explored by the Inventory ("Professional and Institutional Socialization", "Social and Emotional Aspects", "Learning and Professional Development", "Support/Resources/Supervision” and "Vocational Aspects”), results suggest higher levels of satisfaction and major gains on "Institutional and Professional Socialization", "Learning and Professional Development" and "Vocational Aspects" dimensions.

Keywords: Practicum (preservice program); Young-adults development; University-work transition; Teachers’ education.
\end{abstract}

\section{Introdução}

Surgindo o estágio pedagógico como o culminar da formação inicial de professores e, para muitos dos alunos das licenciaturas em Ensino, como o primeiro "mergulho" no mundo da docência, este é tido, por alguns autores, como um dos momentos mais importantes do desenvolvimento profissional dos jovens candidatos (Britzman, 1991; Machado, 1996; Simões, 1996; Capel, Leask \& Turner, 1997; Caires \& Almeida, 2001a). Alargando o impacto desta componente da formação inicial a todo o percurso desenvolvimental do professor, Simões (1996) assume o

Endereço para correspondência:

${ }^{1}$ E-mail: leandro@iep.uminho.pt

${ }^{2}$ E-mail: caires@iep.uminho.pt estágio pedagógico como “...um período único e significativo na vida pessoal e profissional de qualquer professor" (p. 132). No mesmo sentido, Capel e colaboradores (1997), enfatizando a riqueza e intensidade das aprendizagens ocorridas nesta etapa formativa, afirmam que, durante o estágio pedagógico, o candidato a professor constrói o seu repertório de competências e conhecimentos, e desenvolve a sua capacidade de avaliação profissional de uma forma mais rápida e intensa do que em qualquer outra etapa do seu desenvolvimento profissional.

Após um período de cerca de 16 anos no papel de aluno, de entre os quais quatro de preparação para o papel de professor, o jovem candidato tem, finalmente, 
a oportunidade de se estrear "do lado de lá", pondo em prática os conhecimentos que adquiriu nos primeiros anos do curso, testando as teorias, expectativas e representações que foi construindo ao longo do mesmo, e fazendo pequenos ensaios rumo à edificação de um estilo próprio de actuação (Meijer, Zanting \& Verloop, 2002; Oliveira, 1992; Ryan, Toohey \& Hughes, 1996). Ao longo desta etapa da sua profissionalização, são múltiplas as oportunidades que se lhe oferecem nesse sentido, quer através da observação de profissionais mais experientes, quer pela experienciação directa e reflexão sobre o acto de ensino, quer, ainda, pela exploração do meio e das diferentes "ferramentas" que este lhe oferece. Segundo Schön (1987), este confronto directo com situações de prática real, a resolução de problemas concretos e a interacção com outros participantes são determinantes à iniciação destes neófitos nas convenções, saberes e linguagens específicas da profissão. A experimentação activa e o diálogo com a própria acção permitem a tomada de consciência das exigências, dificuldades e desafios que a profissão lhes reserva, bem como das limitações e potencialidades do próprio formando.

No contexto específico da formação inicial de professores do 3o ciclo do Ensino Básico e do Ensino Secundário, a imersão dos formandos em contextos e situações reais de trabalho ocorre (regra geral) com os estágios pedagógicos, momento em que são colocados numa escola (na condição de professores contratados) e em que assumem a responsabilidade pela docência de uma ou duas turmas. Ao longo de um ano lectivo completo, e por meio de uma verdadeira metodologia do aprender fazendo, o neófito tem a oportunidade de construir activamente uma forma pessoal de conhecer, bem como de se familiarizar com as normas, os valores e a cultura de uma classe profissional que está prestes a integrar. O seu envolvimento num conjunto de papéis, actividades e responsabilidades, de âmbito e natureza diversa, em interacção com diferentes agentes, e encerrando diversos desafios e níveis de exigência e reflexão, fazem do estágio pedagógico um espaço privilegiado do desenvolvimento pessoal e profissional dos candidatos a professores.

De entre os desafios e exigências contidos nesta sua iniciação à prática profissional destaquem-se o extenso rol de conhecimentos, procedimentos, rotinas e destrezas que é esperado que o aprendiz de professor assimile e passe a dominar, aplicando-os nos diferentes "palcos" em que o professor actua (sala de aula, sala de professores, nos distintos espaços da escola) e na interacção com diversos actores (alunos, outros professores, pais/encarregados de educação, funcionários, membros do Conselho Executivo...). A planificação das aulas, o falar em público, o desenvolvimento e a aplicação de estratégias de ensino capazes de tornar os conteúdos mais acessíveis e motivantes para os alunos, ou o domínio dos conteúdos/matérias a ensinar, são disso exemplos. A estes acrescentem-se a familiarização com os programas e o seu cumprimento, a gestão do tempo e dos comportamentos em sala de aula, a promoção e avaliação das aprendizagens dos alunos, ou o conhecimento da dinâmica do grupo-turma e dos seus diferentes ritmos de aprendizagem. Não esquecer, ainda, a participação em reuniões (de avaliação, do conselho disciplinar...), a organização de actividades extracurriculares, e a aquisição de conhecimentos básicos no nível de legislação sobre o Ensino e das burocracias inerentes à profissão docente (Head, Hill \& Maguire, 1996; Pacheco, 1995; Shulman, 1987).

$\mathrm{O}$ carácter diverso das actividades, práticas e interacções que têm lugar no âmbito dos estágios pedagógicos, aparece referido como importante motor do desenvolvimento dos professores neófitos, em diversas áreas do seu funcionamento (Caires, 2003; Glickman, Gordon \& Ross-Gordon, 1998; McNally et al., 1997; Sanches \& Petrucci, 2002). Os ganhos daí decorrentes traduzem-se, geralmente, em actuações de progressiva eficácia, flexibilidade e espontaneidade, ou em crescentes destrezas na tomada de decisões e na resolução de problemas. Uma maior capacidade de adaptação às diferentes situações e uma crescente disponibilidade para os alunos, para a satisfação das suas necessidades e ritmos individuais, ou crescentes competências ao nível metacognitivo, são igualmente apontados como representando algumas das evoluções sofridas ao longo do estágio (Caires, 2001; Fuller, 1969; Kagan, 1992). Outros autores salientam, ainda, o impacto do estágio pedagógico no desenvolvimento vocacional destes quase-adultos e quase-profissionais. Atendendo à proximidade da sua entrada no mundo do trabalho, o estágio constitui uma oportunidade ímpar para a clarificação e problematização de vários aspectos relacionados com os seus projectos vocacionais, nomeadamente no que diz respeito ao estilo de vida a adoptar e ao rumo profissional a seguir (Caires \& Almeida, 2001b; Machado, 1996; Mendes, 2002; Serow, 1998).

A par dos múltiplos "crescimentos" mencionados, são, também, várias as dificuldades $\mathrm{e}$ constrangimentos vivenciados pelos professoresestagiários. $\mathrm{O}$ acumular de tarefas e responsabilidades inerentes ao seu duplo papel de aluno e professor, a constante avaliação a que se encontram sujeitos e a necessidade de demonstrar competência junto das várias audiências ou, entre outros, "o ter que entrar numa rede de relacõoes já existente, e a necessidade de construir um perfil de sucesso que garanta a sua credibilidade na instituição escolar" (Cavaco, 1990, p. 48-9), justificam os elevados níveis de desgaste, tensão, stresse e insegurança frequentemente 
relatados pelos estagiários (Caires, 2001; Head et al., 1996; Jesus \& Esteve, 1997; Machado, 1996).

Alguns autores falam, inclusive, do "choque da realidade", ilustrando o forte impacto deste primeiro confronto com a docência (Caires, 2001; Machado, 1996; Mendes, 2002; Morton et al., 1997; Veenman, 1984), associado, por exemplo, à constatação de discrepâncias entre as imagens construídas ao longo do seu percurso anterior e a realidade com que se debatem no "regresso à escola", ao desfasamento entre a teoria e a prática ou, por exemplo, às expectativas muito elevadas em relação ao seu sucesso enquanto futuros professores.

Refira-se, no entanto, os impactos diferenciados que esta experiência poderá ter entre os diferentes formandos. A melhor ou pior forma como são encaradas e resolvidas algumas das dificuldades $\mathrm{e}$ desafios colocados ao jovem, e ao profissional em formação, depende de variáveis de ordem diversa. A par das características e recursos pessoais do sujeito, o apoio recebido em termos de supervisão e o ambiente de trabalho e da escola parecem desempenhar um papel fundamental na forma como os estagiários ultrapassam as dificuldades inerentes a um dos períodos mais exigentes e desafiantes do seu percurso formativo (Alarcão \& Tavares, 2003; Caires, 2001; Galvão, 1996; McNally et al., 1994, 1997; Oliveira, 1992).

Muitos dos anteriores aspectos (e suas sinergias) são, no entanto, raramente explorados em termos da investigação nesta área que, apesar de extensa, constitui um retrato pouco fiel da verdadeira complexidade do Tornar-se professor. Com efeito, das várias tentativas encetadas no sentido de estudar a entrada dos professores neófitos no mundo da docência, muitas têm-se cingido a leituras parciais deste processo. Assim, enquanto umas estão mais centradas na estrutura/ organização dos estágios, algumas orientam-se para o processo de socialização profissional subjacente, reportando-se outras, por exemplo, à exploração da vertente cognitiva do aprender a ensinar e/ou das destrezas adquiridas durante o primeiro ano de prática. A análise do fenómeno, pela sua complexidade, não pode, no entanto, ser dissociada da pessoa no seu todo, das relações com os outros, ou dos acontecimentos e dos contextos em que tem lugar. É na sinergia e na conflitualidade entre as diferentes dimensões do funcionamento do indivíduo, em interacção com todo um conjunto de variáveis contextuais, que o desenvolvimento ocorre (Alarcão \& Sá-Chaves, 1994; Alarcão \& Tavares, 2003; Britzman, 1991; Bullough, Knowles \& Crow, 1991; Caires, 2003; Machado, 1996).

Foi partindo de uma concepção desenvolvimentista e ecológica do Tornar-se Professor, e tomando como referência o repertório experiencial dos seus protagonistas, que se deu "corpo" a um dos nossos mais recentes investimentos em matéria de investigação sobre os estágios do Ensino Superior: a construção e validação do Inventário de Vivências e Percepções de Estágio Versão para as Licenciaturas em Ensino (IVPE-ES(LE)). O presente instrumento serviu de base a um estudo realizado, no ano lectivo de 2000/2001, com um grupo de professores-estagiários da Universidade do Minho. Aplicado no início e no final do estágio, o IVPEES(LE) procurou explorar algumas das vivências mais significativas associadas a estes dois momentos do estágio, averiguando, igualmente, as áreas de percepção de maior ganho e evolução pessoal e profissional.

\section{Metodologia}

\section{Amostra}

O estudo contou, inicialmente, com um total de 296 professores-estagiários $(82,5 \%$ do universo de alunos que, no ano lectivo de 2000/01, se encontravam inscritos no estágio pedagógico), oriundos de duas grandes áreas de formação: Letras e Humanidades $(\mathrm{n}=$ 165) e Ciências ( $\mathrm{n}=131)$. Num segundo momento (final do estágio) o número de participantes viu-se reduzido a 229 sujeitos, assistindo-se a uma diminuição da amostra em 23\% do seu tamanho inicial. Para efeitos deste estudo, passaremos a considerar, apenas, os professores-estagiários que estiveram presentes nas duas aplicações do IVPE-ES(LE). Entre o grupo das Letras e Humanidades $(\mathrm{n}=121)$ participaram sujeitos dos cursos de licenciatura em Ensino de Português ( $\mathrm{n}=21$ alunos), Português-Inglês $(n=31)$, Português-Alemão $(n=12)$, Português-Francês ( $\mathrm{n}=18)$, Inglês-Alemão $(\mathrm{n}=26)$ e História $(\mathrm{n}=13)$. Ao grupo de Ciências $(\mathrm{n}=108)$ corresponderam os alunos dos cursos em Ensino da Física e da Química ( $\mathrm{n}=33$ ), da Biologia e da Geologia ( $\mathrm{n}=31)$ e da Matemática $(\mathrm{n}=44)$.

Refira-se, na amostra, o predomínio de sujeitos do sexo feminino (85.2\%), muito embora com um menor desfasamento masculino/feminino entre os alunos de Ciências. Em termos etários, as idades dos sujeitos oscilaram entre o valor mínimo de 21 anos e o máximo de 52, este último observado entre um aluno do curso de Português (no grupo de Ciências a idade máxima situou-se nos 43 anos). Relativamente à média das idades destes dois grandes grupos, os seus valores aproximam-se (24.08 nas Letras e 24.09 nas Ciências), embora com maior variabilidade entre os alunos de Letras e Humanidades.

\section{Instrumento}

$\mathrm{O}$ acesso ao repertório experiencial destes professores-estagiários foi possível através da aplicação do IVPE-ES(LE), instrumento construído e validado no âmbito do projecto de doutoramento da primeira 
autora (Caires, 2003). Centrado na óptica do formando, este Inventário conta com um total de 61 itens, 51 dos quais organizados de acordo com uma escala likert de cinco pontos (de discordo totalmente a concordo totalmente), três outros encerrando, simultaneamente, uma componente likert e uma componente aberta (pedindose, nesta última, que se proceda à justificação da resposta na parte likert) e, finalmente, sete itens "qualitativos" onde se solicita ao estagiário uma apreciação de vários aspectos do estágio (e.g., sentimentos positivos e negativos, principais preocupações, aspectos positivos e negativos da supervisão assegurada pelos orientadores da escola e da universidade).

Procurando cobrir as diferentes facetas da experiência de estágio, os itens do Inventário organizam-se em torno de cinco grandes dimensões/ subescalas: (i) Socialização Profissional e Institucional; (ii) Aprendizagem e Desenvolvimento Profissional; (iii) Aspectos Sócio-Emocionais; (iv) Apoio/Recursos/Supervisão; e (v) Aspectos Vocacionais. Na Tabela 1 é dada a conhecer a distribuição dos itens pelas respectivas dimensões.

Tabela 1 - Inventário de Vivências e Percepções de Estágio (versão para as Licenciaturas em Ensino)

Dimensões

$\begin{array}{lccc}\begin{array}{l}\text { Socialização Profissional } \\ \text { e Institucional }\end{array} & \begin{array}{l}\text { Aprendizagem e Desen- } \\ \text { volvimento Profissional }\end{array} & \text { Aspectos Sócio-Emocionais Apoio/Recursos/ } & \text { Aspectos Vocacionais }\end{array}$

Itens

\begin{tabular}{|c|c|c|c|c|}
\hline 1. Burocracia & 4. Competências & 5. Auto-imagem & 3. Acompanhamento & 2. Sentir-se professor/ \\
\hline 6. Relação outros & adquiridas & 10. Deslocações escola & supervisores & identidade profissional \\
\hline professores & 9. Articulação teoria- & 16. Desgaste físico & 8. Apoio emocional & 7. Colocação $(*)$ \\
\hline 12. Piores turmas & prática & 25. Medicação & supervisores & 14. Receio mundo \\
\hline 15. Abertura à iniciativa & 13. Estágio variado & 27. Outro núcleo & 11a. Definição objectivos & profissional \\
\hline 17. Funcionamento escola & 23. Partilha colegas & 30. Tensão & de estágios & 18. Outro curso/ \\
\hline 20. Trabalho em equipa & 29. Estágio como & 36. Maior à vontade $(*)$ & 11b. Critérios de avaliação & profissão \\
\hline 24. Recursos disponibili- & complemento 1 os anos & 42. Falta dos mais & 19.Controlo supervisores & 21. Vocação \\
\hline zados & 35. Prefere universidade & significativos & $(*)$ & 32. Novo curso \\
\hline 26. Conquista & 41. Formação prévia & 44. Desgaste psicológico & 22. Articulação & 37.1. Realização pessoal \\
\hline reconhecimento & 55. Importância estágio & 47. Problemas de sono & escola/universidade & 37.2. Realização \\
\hline $\begin{array}{l}\text { 31. Acolhimento caloroso } \\
\text { 34. Horários escola }\end{array}$ & 60. Crescimento pessoal & $\begin{array}{l}\text { 49. Falta de com quem } \\
\text { partilhar }\end{array}$ & $\begin{array}{l}\text { 28. Falta orientação } \\
\text { concreta }\end{array}$ & $\begin{array}{l}\text { profissional } \\
\text { 37.3. Estilo de vida }\end{array}$ \\
\hline 38. Baixo estatuto & & 51. Competição colegas & 33. Supervisão como & 37.4. Estatuto Social \\
\hline estagiário & & 53. Hábitos/padrões & espaço de crescimento & 37.5. Bem estar financeiro \\
\hline 40. Relação alunos & & alimentares & 46. Recursos universidade & 39. Formação contínua \\
\hline 45. Outra escola & & 56. Desiste estágio & 61. Aspectos positivos & 43. Auto-eficácia \\
\hline 48. Falta de sintonia & & 57. Preocupações/ & supervisão universidade & \\
\hline 50. Relação Cons. Exec. & & Necessidades/Dificuldades & 62. Aspectos negativos & \\
\hline 52. Meio circundante & & 58. Sentimentos positivos & supervisão universidade & \\
\hline 54. Desilusão Sist. Ens. & & 59. Sentimentos negativos & $\begin{array}{l}\text { 63. Aspectos positivos } \\
\text { supervisão escola } \\
\text { 64. Aspectos negativos } \\
\text { supervisão escola }\end{array}$ & \\
\hline
\end{tabular}

Legenda: Itens a itálico são meramente qualitativos; itens com $(*)$ foram eliminados por afectarem negativamente a consistência interna

A dimensão (i) Socialização Profissional e Institucional reporta-se à socialização do estagiário, explorando-se a qualidade da integração do neófito na instituição de acolhimento e na própria profissão, os recursos que the foram disponibilizados ou, por exemplo, as principais dificuldades vivenciadas na adaptação às regras e rotinas da instituição. No que se refere à dimensão (ii) Aprendizagem e Desenvolvimento Profissional, os seus itens exploram o contributo que a vertente mais prática do curso poderá ter em termos da preparação destes formandos para o desempenho da profissão. Competências e conhecimentos adquiridos, destrezas desenvolvidas, grau de abrangência e diversidade das experiências de aprendizagem ou, ainda, o nível de auto-eficácia percebido por estes alunos, são alguns dos principais aspectos aqui abarcados. $\mathrm{Na}$ dimensão (iii) Aspectos Sócio-Emocionais, a ênfase é dada à exploração do impacto do estágio ao nível intra e interpessoal, encerrando aqui variáveis psicossociais (auto-estima, sentido de auto-eficácia...) e psicofisiológicas (sono, apetite...), e considerando a intensidade e o sentido de algumas das alterações 
ocorridas. Os itens da dimensão (iv) Apoio/Recursos/ Supervisão exploram o apoio e o acompanhamento assegurados durante o estágio, bem como o grau de satisfação do estagiário relativamente a cada um deles. Sendo o supervisor apontado como um elemento determinante do grau de satisfação e de formação do estagiário (Alarcão \& Tavares, 2003; Galvão, 1996; Glickman \& Bey, 1990), este surge como uma das figuras centrais aqui exploradas. Por último, na dimensão (v) Aspectos Vocacionais considera-se o questionamento dos estagiários no confronto com a profissão, em termos da "vocação" detida e do grau de realização pessoal e profissional antecipado. Algumas questões relativas à sua inserção no mercado de trabalho, à satisfação com o curso escolhido e à possibilidade de ingressar numa segunda área ou de prosseguir estudos são, também, aqui contempladas.

\section{Procedimentos}

Tal como anteriormente referido, a recolha dos dados teve lugar em dois momentos do estágio: um mês após o arranque do estágio (outubro) e um mês antes do seu desfecho (maio). Os professores-estagiários foram convocados via carta, nas respectivas escolas, e, na data combinada, deslocaram-se à Universidade do Minho a fim de preencherem o Inventário. Não sendo pedida a identificação pessoal dos sujeitos (por forma a assegurar o anonimato e a autenticidade das suas respostas), foi necessário criar um procedimento que permitisse a identificação do processo de cada aluno (primeiro e segundo questionário preenchidos). Assim sendo, foi pedido a cada sujeito que criasse o seu próprio código de identificação, ao qual só este e o investigador tinham acesso. Tal código - contendo quatro dígitos e/ou letras - era inscrito dentro de um envelope, com o nome do aluno do lado de fora, sendo posteriormente selado e só reaberto (pelo próprio) na segunda aplicação do questionário.

\section{Resultados}

$\mathrm{Na}$ Tabela 2 apresentam-se os dados relativos à distribuição das respostas dos sujeitos nas cinco dimensões do IVPE-ES (LE), considerando os dois momentos do estudo. A par das médias por dimensão, considerou-se oportuno acrescentar, dentro de parêntesis, a média das pontuações atribuídas aos itens em cada dimensão, por forma a facilitar uma análise comparativa dos resultados. De referir que valores mais altos nas médias traduzem maiores índices de satisfação ou vivências pautadas por menores dificuldades.

Tabela 2 - Resultados nas cinco subescalas do IVPE-ES(LE)

\begin{tabular}{|c|c|c|c|c|c|c|}
\hline \multirow[b]{2}{*}{ Dimensões } & \multicolumn{3}{|c|}{ INÍCIO ESTÁGIO (A) } & \multicolumn{3}{|c|}{ FINAL ESTÁGIO (C) } \\
\hline & Média & D. P. & Mín-Máx & Média & D. P. & Mín-Máx \\
\hline Socialização (17 itens) & $59.0(3.47)$ & 8.75 & $30-81$ & $62.9(3.70)$ & 8.71 & $37-85$ \\
\hline Sócio-emocion (13 itens) & $40.7(3.13)$ & 7.93 & $18-62$ & $41.7(3.21)$ & 8.80 & $18-62$ \\
\hline Vocacional (12 itens) & $42.9(3.58)$ & 6.22 & $15-56$ & $45.4(3.78)$ & 5.57 & $28-57$ \\
\hline Supervisão (9 itens) & $29.0(3.22)$ & 5.36 & $15-45$ & $29.9(3.32)$ & 5.15 & $15-43$ \\
\hline Aprendizagem (9 itens) & $31.2(3.47)$ & 4.36 & $17-45$ & $33.3(3.70)$ & 3.99 & $21-42$ \\
\hline
\end{tabular}

Olhando os valores da Tabela 2, constatam-se algumas mudanças nas vivências e percepções dos alunos entre o início e o final do estágio. Recorrendo ao t-test para a análise da diferença de médias em amostras emparelhadas, verificou-se que tais mudanças são estatisticamente significativas no que se refere ao grau de adaptação percebido pelos professores-estagiários em termos da sua inserção na escola e na profissão ( $t=$ 4.806; g.l.=224; $\mathrm{p}<0.001)$, aos ganhos decorrentes do estágio em termos de aprendizagem ( $\mathrm{t}=-5.166$; g.l. $=224$; $\mathrm{p}<0.001)$ e às questões do foro vocacional $(\mathrm{t}=-4.962$; g.l.=224; $\mathrm{p}<0.001)$.

No que se refere à dimensão "Socialização Profissional e Institucional", as diferenças observadas apontam para a conquista de maiores níveis de integração no final do estágio, e para a presença de níveis de satisfação bastante razoáveis (próximos do nível 4 na escala de likert) em relação a aspectos como o apoio e acolhimento recebidos no seio da instituição, os recursos e as dinâmicas da escola, ou os diferentes interlocutores com quem teve a oportunidade de conviver e trabalhar. $\mathrm{O}$ mesmo tipo de tendência foi 
encontrado nas respostas à dimensão "Aprendizagem e Desenvolvimento Profissional", indiciando o impacto positivo do estágio na capacitação profissional destes candidatos a professores. Os resultados obtidos apontam para a superação de algumas das dificuldades "técnicas" vividas no início do estágio, apresentando os sujeitos, no final, maiores níveis de confiança/satisfação relativamente às competências adquiridas. No que se refere aos "Aspectos Vocacionais", os valores obtidos indiciam uma identidade profissional mais consolidada no final do estágio, uma maior satisfação com a escolha vocacional realizada e/ou maiores níveis de confiança relativamente à sua "vocação" para a docência.

Em relação aos resultados nas duas restantes subescalas do Inventário ("Aspectos Sócio-Emocionais e "Apoio/Recursos/Supervisão"), é de referir que, muito embora, entre o início e o final do estágio, se tenham registado mudanças no sentido positivo (cf. quadro II), estas não assumiram significado estatístico.
Estas foram, aliás, as duas áreas que, já no início do estágio, se revelaram como mais "fragilizadas" em termos do repertório de vivências dos estagiários avaliados. Saliente-se, mesmo assim, a presença de pontuações ligeiramente superiores ao ponto três, sugerindo um nível mediano de satisfação/dificuldade.

A corroborar a evolução positiva nas percepções e vivências dos estagiários - nomeadamente nas três dimensões com uma mudança estatisticamente significativa - podemos tomar os testemunhos dos sujeitos em resposta ao item 60 do IVPE-ES(LE) "Sinto que o estágio me tem levado/me levou a crescer como pessoa". Especificamente centrado na exploração dos ganhos ocorridos, as respostas a este item acabaram por dar expressão aos ganhos ocorridos noutras áreas do seu funcionamento. A Tabela 3 dá a conhecer a distribuição das respostas dos sujeitos pelas cinco categorias emergidas na análise de conteúdo realizada.

Tabela 3 - Crescimento pessoal associado à experiência de estágio, no início e no final do estudo (número de elicitações)

\begin{tabular}{lcc}
\hline Categorias & Início Estágio & Final Estágio \\
\hline 1. Intrapessoais & $168(41.9 \%)$ & $162(47.5 \%)$ \\
2. Interpessoais & $96(23.9 \%)$ & $80(23.5 \%)$ \\
3. Comp. Profissionais & $80(20 \%)$ & $65(19.1 \%)$ \\
4. Vocacionais & $42(10.5 \%)$ & $15(7.3 \%)$ \\
5. Autonomia Financeira & $9(2.24 \%)$ & $4(1.2 \%)$ \\
Outros $\left(^{*}\right)$ & $6(1.5 \%)$ & $5(1.5 \%)$ \\
Total & 401 & 341 \\
\hline
\end{tabular}

(*) Esta categoria abarcou respostas que, pelo seu carácter particular, pela sua indefinição ou carácter vago, não foi possível integrar em qualquer outra categoria. Delas são exemplo respostas como "Aprende mais do que na Universidade", "Atinge objectivos" ou "Esclarece receios".

Entre os ganhos evocados por estes candidatos, destacam-se o maior número de elicitações feitas às esferas intra e interpessoais, para as quais, aliás, se orienta o item 60. Assim, entre os "crescimentos" ocorridos em termos intrapessoais, são de salientar as alusões feitas aos maiores níveis de auto-estima e autoconfiança conquistados, ao maior auto-controlo adquirido e à maior "calma para encarar os problemas". Uma maior determinação, auto-disciplina ou "firmeza nas decisões" parecem significar que, para alguns destes futuros professores, o estágio representou um impulsionador do "carácter mais firme" conquistado. De referir, também, as elicitações dos sujeitos sugerindo uma maior "maturidade", à qual se associam respostas do tipo "maior realismo", "discernimento", um "maior sentido de responsabilidade" ou "ponderação". Uma maior auto-reflexão, uma maior consciência das suas próprias limitações ou o "saber o que não quero" ilustram, também, o maior auto-conhecimento adquirido em resultado da experiência de estágio.

No que diz respeito às respostas que remetem para os ganhos ocorridos ao nível interpessoal, as verbalizações dos sujeitos apontam para uma crescente abertura aos outros (auto-descentração, altruísmo, maior abertura à opinião dos outros...) e um maior à vontade nas relações estabelecidas (assertividade, desinibição, "segurança interpessoal"...). De destacar, ainda, as alusões feitas ao crescimento ocorrido no seio das relações, à troca de experiências, à cumplicidade conquistada, e a algumas das amizades construídas ou consolidadas durante o estágio.

No que se refere à categoria "Competências profissionais", as respostas dos sujeitos dispersaram-se entre elicitações mais vagas (e.g., "abrir de horizontes", aquisição de conhecimento profissional, experiência de vida e/ou profissional) e o desenvolvimento de competências profissionais mais específicas (liderança, identificação das dificuldades dos alunos, competências 
linguísticas...), passando, ainda, por um conjunto de competências que aqui designámos de "potencial de crescimento". Estas últimas reúnem um conjunto de características que, em nosso entender, poderão constituir-se em elementos-chave do desenvolvimento profissional destes candidatos a professores. Delas são exemplo a auto-crítica, a curiosidade, o gosto pelo conhecimento, a vontade de ir mais longe ou de querer dar o seu melhor. O espírito crítico, a reflexão contínua, a capacidade de pedir ajuda e de aprender com os erros surgiram, igualmente, entre os testemunhos dos estagiários, sendo vários deles apontados na literatura como essenciais ao desenvolvimento profissional dos professores (Alarcão, 1996; Alarcão \& Tavares, 2003; Nóvoa, 1991; Schön, 1987).

Finalmente, e referindo-nos às respostas dos sujeitos mais centradas nos ganhos ocorridos na esfera vocacional, o "sentir-se útil", o "guiar os alunos", a "concretização de um sonho" ou o prazer decorrente do "ajudar alguém" vão, uma vez mais, ao encontro daquilo que autores como Serow (1998) e Newman (2000) classificam como uma espécie de "chamamento", e que alguns destes alunos parecem sentir. A confirmação ou a descoberta da sua "vocação" para o ensino, a edificação da sua identidade como professor, ou o sentimento de realização pessoal e/ou profissional fizeram também parte das verbalizações destes sujeitos perdendo, no entanto, alguma expressão na fase final do estágio. $\mathrm{Na}$ origem da diminuição de "entusiasmo" observada poderão estar, por exemplo, as dificuldades antecipadas em termos de inserção no mercado de trabalho, a indefinição e a instabilidade dos primeiros anos de prática ou o significativo desgaste físico e psicológico associados ao desempenho da profissão (deslocações, elevados índices de indisciplina, constantes mudanças no Sistema de Ensino...).

\section{Conclusão}

A síntese de evidências empíricas e teóricas realizada ao longo deste trabalho parece deixar bem claro o carácter complexo, dinâmico, polifacetado e multicontextual do Tornar-se professor. Encerrando uma multiplicidade de dimensões e tarefas desenvolvimentais, bem como um conjunto de factores de ordem pessoal, relacional, institucional e formativa, sinergicamente implicados, o estágio pedagógico emerge como uma das etapas mais ricas e de maior impacto na formação inicial dos professores.

Abarcando não meramente uma vertente técnica, conceptual ou procedimental, este serve de palco a uma verdadeira "revolução" pessoal, atingindo diferentes facetas do desenvolvimento do professor neófito. Assim, neste encontro com a profissão docente e no "descobrir-se no papel de professor" são várias as mudanças e crescimentos que poderão ocorrer, designadamente no que se refere à percepção que tem de si próprio, do seu valor e capacidade para fazer frente aos desafios da docência, dos afectos, objectivos e interesses em relação à profissão ou, por exemplo, na sua forma de estar e de se relacionar com os outros (Bullough et al., 1991; Machado, 1996; McNally et al., 1997; Mendes, 2002). Exemplo disso foram os resultados encontrados no nosso estudo, sugerindo mudanças positivas na auto-estima e auto-eficácia dos sujeitos, no questionamento vocacional ou nas suas competências de comunicação e de relacionamento interpessoal. Estes dados corroboram, assim, a multiplicidade de facetas que são "tocadas" pela experiência de estágio.

A terminar, atendendo ao significativo impacto deste momento formativo no desenvolvimento global dos futuros professores, justifica-se a consolidação da investigação nesta área, capaz de explorar e integrar as múltiplas complexidades dos estágios pedagógicos e as vivências e percepções associadas à sua experienciação na primeira pessoa. Nesse sentido, sugere-se que, a par da identificação e compreensão dos diversos factores (actores, papéis, contextos, currículos...) e sinergias que concorrem para este processo, se atenda à pessoa do formando. Tal como sugerem Simões e colaboradores (1997), é necessário continuar a explorar "quem" são estes indivíduos, e, sobretudo, "em que é que" e "como" se vão tornando professores. $\mathrm{O}$ passado destes candidatos (percurso escolar, opção pelo Ensino...), o seu presente (motivações, crenças e representações detidas acerca do Ensino e da carreira docente), e o seu futuro na profissão, parecem-nos justificar uma maior atenção por parte dos investigadores e gestores académicos em relação a este momento formativo, assumindo-se, desde logo, uma perspectiva biográfica, ecológica e desenvolvimentista do aprender a ensinar.

\section{Referências}

Alarcão, I. (1996). Formação reflexiva de professores: estratégias de supervisão. Porto: Porto Editora.

Alarcão, I. \& Sá-Chaves, I. (1994). Supervisão de professores e desenvolvimento humano. Uma perspectiva ecológica. Em J. Tavares (Org.). Para intervir em Educação. Contributos dos Colóquios CIDInE (p. 203-232). Aveiro: CIDInE.

Alarcão, I. \& Tavares, J. (2003). Supervisão da prática pedagógica: uma perspectiva de desenvolvimento e aprendizagem. 2. ed. Coimbra: Livraria Almedina.

Britzman, D. P. (1991). Practice makes practice: A critical study of learning to teach. Albany: State University of New York Press. 
Bullough, R. V. Jr., Knowles, J. G. \& Crow, N. A. (1991). Emerging as a teacher. London: Routledge.

Caires, S. (2001). Vivências e percepções do estágio no Ensino Superior. Braga: Universidade do Minho, Grupo de Missão para a Qualidade do Ensino/Aprendizagem Apontamentos U. M.

Caires, S. (2003, no prelo). Vivências e percepções do estágio pedagógico: a perspectiva dos estagiários da Universidade do Minho. Tese (Doutoramento em Psicologia da Educação). Braga: Universidade do Minho - Departamento de Psicologia.

Caires, S. \& Almeida, L. S. (2001a). O estágio como um espaço de desenvolvimento de competências pessoais e profissionais: o papel da supervisão. Em A. Gonçalves, L. S. Almeida, R. M. Vasconcelos \& S. Caires (Eds.). Actas do seminário da universidade para o mundo do trabalho: desafios para um diálogo (p. 227246). Braga: Universidade do Minho, Conselho Académico.

Caires, S. \& Almeida, L. S. (2001b). Possíveis contributos do estágio para o desenvolvimento vocacional: estudo com alunos universitários. Psychologica, 26, 187-198.

Capel, S., Leask, M. \& Turner, T. (1997). Starting to teach in the secondary school: A companion for the newly qualified teacher. London and New York: Routledge.

Cavaco, M. H. (1990). Retrato do professor enquanto jovem. Revista Crítica de Ciências Sociais, 29, 121-138.

Fuller, F. F. (1969). Concerns of American teachers: A developmental conceptualization. American Educational Research Journal, 29, 325-349.

Galvão, C. (1996). Estágio pedagógico - Cooperação na formação. Revista de Educação, VI(1), 71-87.

Glickman, C. D. \& Bey, T. M. (1990). Supervision. Em W. R. Houston (Ed.). Handbook of research on Teacher Education (p. 549-566). New York: Macmillan.

Glickman, C. D., Gordon, S. P. \& Ross-Gordon, J. M. (1998). Supervision of instruction: A developmental approach (4th ed.). Massachusetts: Allyn \& Bacon.

Head, J., Hill, F. \& Maguire, M. (1996). Stress and the postgraduate secondary school trainee teacher: A British case study. Journal of Education for Teaching, 22(1), 71-84.

Jesus, S. N. \& Esteve, J. M. (1997). O treino de inoculação ao stress na formação inicial de professores. Actas do I Congresso Luso-Espanhol de Psicologia da Educação (p. 148-152). Coimbra: APPORT/Colégio Oficial de Psicólogos.
Kagan, D. M. (1992). Professional growth among preservice and beginning teachers. Review of Educational Research, 62(2), 129-169.

Machado, C. G. (1996). Tornar-se professor - da idealização à realidade. Tese (Doutoramento em Psicologia Educacional). Évora: Universidade de Évora Departamento de Pedagogia e Educação.

McNally, J., Cope, P., Inglis, B. \& Stronach, I. (1994). Current realities in the student teaching experience: A preliminary inquiry. Teaching and Teacher Education, 10(2), 219-231.

McNally, J., Cope, P., Inglis, B. \& Stronach, I. (1997). The student teacher in school: Conditions for development. Teaching and Teacher Education, 13(5), 485-498.

Meijer, P. C., Zanting, A. \& Verloop, N. (2002). How can student teachers elicit experienced teachers' practical knowledge? Journal of Teacher Education, 53(5), 406-419.

Mendes, P. S. (2002). A formação inicial de professores e o choque da realidade: expectativas e vivências sobre o ano de estágio. Tese de Mestrado em Educação, na especialidade de Supervisão Pedagógica. Évora: Universidade de Évora -Departamento de Pedagogia e Educação.

Morton, L. L., Vesco, R., Williams, N. H. \& Awender, M. A. (1997). Student teacher anxieties related to class management, pedagogy, evaluation, and staff relations. British Journal of Educational Psychology, 67, 69-89.

Newman, C. S. (2000). Seeds of professional development in preservice teachers: A study of theirs dreams and goals. International Journal of Educational Research, 33(2), 125-217.

Nóvoa, A. (1991). Concepções e práticas de formação contínua dos professores. Em J. Tavares (Org.). Formação contínua de professores - realidades e perspectivas (p. 15-38). Aveiro: Universidade de Aveiro.

Oliveira, L. (1992). O clima e o diálogo na supervisão de professores. Cadernos CIDInE, 5, 13-22.

Pacheco, J. A. (1995). Currículo: teoria e práxis. Porto: Porto Editora.

Ryan, G., Toohey, S. \& Hughes, C. (1996). The purpose, value and structure of the practicum in the Higher Education: A literature review. Higher Education, 31, 355-377.

Sanches, M. F. C. \& Petrucci, R. (2002). Revista de Educação, XI(1), 105-128.

Schön, D. A. (1987). Educating the reflective practitioner. San Francisco, CA: Jossey-Bass. 
Serow, R. C. (1998). Called to teach: A study of highly motivated preservice teachers. The Journal of Research and Development in Education, 27(2), 65-72.

Shulman, L. (1987). Knowledge and Teaching: Foundations of the new reform. Harvard Educational Review, 57(1), 1-22.

Simões, C. (1996). O desenvolvimento do professor e a construção do conhecimento pedagógico. Aveiro: Fundação João Jacinto de Magalhães.

Simões, C. M., Santos, M. L., Gonçalves, J. A. \& RalhaSimões, M. H. (1997). A construção da identidade do professor numa perspectiva ecológica de desenvolvimento. Em M. F. Patrício (Org.). Formar professores para a Escola Cultural no horizonte dos anos 2000 (p. 245-260). Porto: Porto Editora.

Veenman, S. (1984). Perceived problems of beginning teachers. Review of Educational Research, 54(2), 143-178.

Recebido em agosto de 2003 Reformulado em novembro de 2003 Aprovado em dezembro de 2003

Sobre os autores:

Susana Caires é mestre em Psicologia Escolar, finalizando o doutoramento em Psicologia da Educação pela Universidade do Minho. Assistente desta Universidade, lecciona disciplinas de Psicologia nos cursos de Formação de Professores. Vários trabalhos de pesquisa sobre os estágios, a transição para o mundo de trabalho e o início da profissão docente.

Leandro Almeida é doutor em Psicologia da Educação pela Universidade do Porto. Professor catedrático de Psicologia na Universidade do Minho. Presentemente é Presidente do Instituto de Educação e Psicologia dessa Universidade. Lecciona disciplinas sobre avaliação psicológica, cognição e aprendizagem. Coordena um projecto de pesquisa sobre adaptação, desenvolvimento e aprendizagem dos estudantes do Ensino Superior. 
